\title{
The knowledge, attitudes and practices of doctors regarding antibiotic resistance at a tertiary care institution in the Caribbean
}

\author{
Alison Nicholson ${ }^{1 *} \mathbb{D}$, Ingrid Tennant ${ }^{2}$, Livingston White ${ }^{3}$, Camille-Ann Thoms-Rodriguez ${ }^{1}$, Loraine Cook ${ }^{4}$, \\ Stephen Johnson ${ }^{5}$, Tamara Thompson ${ }^{6}$, Jasper Barnett ${ }^{7}$ and Lundie Richards ${ }^{7}$
}

\begin{abstract}
Background: Antibiotic resistance (ABR) is a serious threat that requires coordinated global intervention to prevent its spread. There is limited data from the English-speaking Caribbean.

Methods: As part of a national programme to address antibiotic resistance in Jamaica, a survey of the knowledge, attitudes and antibiotic prescribing practices of Jamaican physicians was conducted using a 32-item self-administered questionnaire.

Results: Of the eight hundred physicians targeted, $87 \%$ responded. The majority thought the problem of resistance very important globally (82\%), less nationally (73\%) and even less (53\%) in personal practices. Hospital physicians were more likely to consider antibiotic resistance important in their practice compared to those in outpatient practice or both $(p<0.001)$. Composite knowledge scores were generated and considered good if scored $>80 \%$, average if 60 $79 \%$ and poor if $<60 \%$. Most had good knowledge of factors preventing resistance (83\%) and resistance inducing potential of specific antibiotics (59\%), but only average knowledge of factors contributing to resistance (57\%). Knowledge of preventative factors was highest in females $(p=0.004)$, those with postgraduate training $(p=0.001)$ and those $>$ four years post graduation $(p=0.03)$. Empiric therapy was often directed by international guidelines and cultures were not routinely done. Limited laboratory and human resources were identified as challenges.
\end{abstract}

Conclusion: Physicians in this study were aware of the problem of ABR, but downplayed its significance nationally and personally. These results will guide a national antibiotic stewardship programme.

Keywords: Antibiotic, Prescribing, Practices, Resistance, Knowledge, Attitudes

\section{Background}

Antibiotic resistance (ABR) has emerged as a significant threat to the quality of health care in the twenty-first century [1]. This, combined with decreased production of new antimicrobial agents, has precipitated a global crisis with the emergence of bacteria resistant to most antibiotics [2-5].

The inability of previously effective antibiotics to treat common bacterial infections has far reaching consequences [1]. The success of many modern advancements in medicine is predicated on the availability and efficacy

\footnotetext{
* Correspondence: alison.nicholson@uwimona.edu.jm

'Department of Microbiology, The University of the West Indies (UWI),

Kingston, Jamaica

Full list of author information is available at the end of the article
}

of antibiotics. These include surgery using prostheses, organ transplantation and chemotherapy [4]. The effects of ABR extend beyond increased mortality $(63,000 /$ year in the US and 25,000/year in the EU) [6] and morbidity to include increased hospital stay and costs. In the USA, ABR has been estimated to cost over 55 billion dollars per annum [7]. In Europe, estimated costs are at least $€ 1.5$ billion per year [6]. However, the real costs are higher when the impact of ABR on the entire health care system and national productivity is taken into account.

Of the over 20 countries in the English speaking Caribbean, data on antibiotic resistance are limited largely to reports from Jamaica, Trinidad and Tobago and Barbados [8-13]. This is concerning, as the Caribbean is a popular destination especially for North 
Americans and Europeans and this would have implications for the types of multiple drug resistant organisms (MDROs) present. A multiple drug resistant organism is defined as one that is resistant to one or more drugs in three or more drug classes [14]. In Jamaica, globally recognized "problem organisms" that have been identified include Methicillin resistant Staphylococcus aureus (MRSA), extended spectrum betalactamases (ESBL) Klebsiella pneumoniae, Escherichia coli and Enterobacter sp., New Delhi metallo-beta-lactamase (NDM-1) Klebsiella pneumoniae, carbapenem resistant Pseudomonas aeruginosa and Acinetobacter spp. as well as Vancomycin resistant Enterococcus (VRE) [13, 15-17]. A 2009 study in a university-affiliated hospital in Kingston, Jamaica showed that resistance among Gram-positive organisms was much lower than among Gram-negative organisms [16].

Antimicrobial abuse is an important cause of ABR and is a compelling target for attention. "Antimicrobial abuse" is an umbrella term for a wide range of breaches including overuse, inappropriate choice, incorrect dosage, incorrect duration of therapy, incorrect dosing interval and suboptimal route of delivery $[4,18]$.

A single-centre study from Jamaica showed that although physicians were aware of $A B R$ and contributing factors, this did not influence their prescribing practices [19]. With a desire to slow the emergence of antimicrobial resistance by determining the strategies necessary to improve prescribing practices among Jamaican physicians, a much larger all island multicentre study was carried out.

\section{Methods}

\section{Aim and study design}

A cross-sectional study was performed to identify the knowledge, attitudes and practices of Jamaican physicians towards antibiotic resistance and antibiotic prescribing practices. This information will help in the development of national antibiotic guidelines and workshops for healthcare workers. A problem with such strong global significance requires every country to define its challenges and make its voice heard.

\section{Study sampling and study instrument}

This study was conducted across Jamaica, the third largest Caribbean island, $11,424 \mathrm{~km}^{2}$, with a population of approximately 2.8 million [20, 21]. Approximately 4000 public and private doctors were identified as currently providing medical care from national registration records (Jamaican Medical Council). We targeted 20\% or 800 doctors. With this sample size, we calculated that we would have a margin of error of $4 \%$ and a $99 \%$ confidence level, assuming a conservative response distribution of $50 \%$. We recruited through medical conferences, hospital meetings and visits to private practices across the four Jamaican health regions- South, Southeast, Northeast and West. Physician registration with the local medical council requires regular attendance at conferences or meetings to obtain continuing medical education credits (CMEs). In addition, we did not target microbiological conferences or those on antibiotics or resistance, but included a wide cross-section of meetings. Therefore, we do not believe that our sample was biased towards physicians with better knowledge of ABR. Data collection was done between October 2014 and September 2015.

The instrument used was a 32-item self-administered questionnaire comprising questions related to demographics (eight questions), knowledge (six questions), attitudes (five questions) and practices associated with antibiotic use (13 questions). Ethical approval was obtained from the Faculty of Medical Sciences, UWI (ECP 183 13/14) and Ministry of Health (MOH) Ethics Committees (2014/26) and informed consent was obtained from each participant.

\section{Data analysis}

Data were analysed using Statistical Analysis in the Social Sciences (SPSS) version 19 and correlations assessed using the Chi-square test. A $p$-value of less than 0.05 was considered statistically significant.

Physicians' knowledge of factors contributing to development of ABR and factors useful in containing resistance were examined. Each factor was analyzed on a scale of 0 to $3(0=$ don't know, $1=$ minimally important, $2=$ moderately important and $3=$ very important) and showed how the respondents ranked their importance. Knowledge of antibiotics more prone to inducing resistance was also assessed, and each was scored between 0 and $2(0=$ don't know, 1 = less likely, $2=$ more likely $)$.

Composite knowledge scores were also calculated. The first score "Factors contributing to development of ABR", represents a computation of 9 variables, each with 4 categories scored from 0 to 3 as follows: $0=$ Don't Know, 1 $=$ Minimally Important, $2=$ Moderately Important, $3=$ Very Important. To ensure the variables were compatible with parametric analysis, the scale variable was converted to an ordinal variable; created by recoding into the following categories ( 9 to15 = Poor knowledge; 16 to 21 = Average knowledge, 22 to $27=$ Good knowledge). This score was then cross-tabulated against physician variables to determine significant predictors.

The second score "Factors useful in containing resistance" was created from 8 variables, each with four categories $(0=$ Don't Know, $1=$ Not Useful, $2=$ May be useful, $3=$ Useful). This scale was recoded into three categories (Poor knowledge $=8-12$; Average knowledge $=$ 13-16; Good knowledge $=17-24$ ). 
The third score "Antibiotics more prone to inducing resistance" (which refers to the potential of an antibiotic to cause the emergence of resistance over time [22]) was created from 7 variables, each with three categories $(0=$ Don't Know, 1 = Less likely, 2 = More likely). The overall score was calculated based on the number of correct responses, with a maximum of 14 points. This scale was recoded into three categories; (Poor knowledge $=0-4$; Average knowledge = 5-9; Good knowledge = 10-14).

Reliability analyses using Cronbach alpha were done to determine the level of internal consistency among the items comprising the individual scales. Results indicated high Cronbach's alpha scores of 0.749 to 0.859 for most of the scales. Only "Factors contributing to development of $A B R$ ” had a lower Cronbach's alpha of 0.631, which is still acceptable [23].

\section{Results}

\section{Respondent demographics}

A total of 695 physicians completed the questionnaire, a response rate of $87 \%$, with $51 \%$ female. The majority stated that their practice was mainly hospital based $(60 \%)$ and $51 \%$ had postgraduate training. About a third $(32 \%)$ were less than four years post registration and $33 \%$ were residents. (Table 1) The Southeast region accounted for $62 \%$ of the respondents, the Western region $22 \%$, the Northeast region $5 \%$ and the Southern region $11 \%$. This corresponded fairly well with data from the Ministry of Health, which indicated the following distribution of physicians: Southeast region 55\%, Western region 20\%, Northeast 15\% and South 10\% (J Barnett, pers. comm.).

\section{Opinion on the magnitude of the problem}

Most of the respondents (82\%) felt the global problem of ABR was very important, but less considered the national problem very important (73\%). In their personal practice, however, only 53\% assessed resistance as being very important; and 15\% did not think it was important at all. Hospital physicians were more likely to consider ABR very important in their practice than outpatient-based, or physicians who practiced in both areas $(65 \%$ vs. $39 \%$ and $35 \%$ respectively, $p<0.001)$.

\section{Knowledge}

\section{Factors contributing to resistance}

Widespread use of antibiotics was thought to be most important, with a mean score of $2.79 \pm 0.48$ followed by overuse of broad-spectrum antibiotics $(2.74 \pm 0.55)$ and inappropriate use of antibiotics $(2.61 \pm 0.60)$. Inadequate hand washing $(1.47 \pm 0.95)$ and use of antibiotics in the livestock industry $(1.41 \pm 1.03)$ were considered least important. (Table 2).
Table 1 Physician Demographics

\begin{tabular}{|c|c|c|c|}
\hline & Category & Frequency & Percent \\
\hline \multirow[t]{2}{*}{ Gender } & Male & 338 & $49 \%$ \\
\hline & Female & 348 & $51 \%$ \\
\hline \multirow[t]{4}{*}{ Current Practice } & $\begin{array}{l}\text { Mainly hospital } \\
\text { based }\end{array}$ & 387 & $60 \%$ \\
\hline & $\begin{array}{l}\text { Mainly outpatient } \\
\text { or clinic based }\end{array}$ & 158 & $25 \%$ \\
\hline & $\begin{array}{l}\text { An equal proportion } \\
\text { of both }\end{array}$ & 97 & $15 \%$ \\
\hline & Total & 642 & $100 \%$ \\
\hline \multirow[t]{8}{*}{ Position } & Intern/SHO & 118 & $17 \%$ \\
\hline & Intern/resident & 186 & $27 \%$ \\
\hline & $\begin{array}{l}\text { Senior/chief } \\
\text { resident }\end{array}$ & 43 & $6 \%$ \\
\hline & Consultant & 156 & $22 \%$ \\
\hline & Private GP & 120 & $17 \%$ \\
\hline & $\begin{array}{l}\text { Specialist private } \\
\text { practice }\end{array}$ & 38 & $5 \%$ \\
\hline & $\begin{array}{l}\text { Government clinic } \\
\text { medical officer }\end{array}$ & 34 & $5 \%$ \\
\hline & Total & 695 & $100 \%$ \\
\hline \multirow{3}{*}{$\begin{array}{l}\text { Postgraduate } \\
\text { Training }\end{array}$} & Yes & 338 & $51 \%$ \\
\hline & No & 328 & $49 \%$ \\
\hline & Total & 666 & $100 \%$ \\
\hline \multirow[t]{8}{*}{ Specialty } & $\begin{array}{l}\text { Anaesthesia/intensive } \\
\text { care }\end{array}$ & 56 & 17 \\
\hline & Internal medicine & 64 & 19 \\
\hline & Surgical specialty & 102 & 31 \\
\hline & Paediatrics & 27 & 8 \\
\hline & $\begin{array}{l}\text { Obstetrics and } \\
\text { gynaecology }\end{array}$ & 24 & 7 \\
\hline & $\begin{array}{l}\text { Accident and } \\
\text { emergency }\end{array}$ & 13 & 4 \\
\hline & Family medicine & 42 & 13 \\
\hline & Clinical microbiologist & 6 & 2 \\
\hline \multirow{7}{*}{$\begin{array}{l}\text { Years Post } \\
\text { Registration }\end{array}$} & Total & 334 & $100 \%$ \\
\hline & $0-4$ years & 218 & $32 \%$ \\
\hline & $5-9$ years & 130 & $19 \%$ \\
\hline & 10-14 years & 87 & $13 \%$ \\
\hline & $15-19$ years & 61 & $9 \%$ \\
\hline & $>_{-} 20$ years & 176 & $26 \%$ \\
\hline & Total & 672 & $100 \%$ \\
\hline
\end{tabular}

N.B. Total sample size for this study is 695 . Differences in totals for each subsection occur because of missing values

Based on their overall score, the majority (57.4\%) had average knowledge, $29.2 \%$ had good knowledge and $13.5 \%$ had poor knowledge of factors contributing to ABR. Higher knowledge of these factors was positively 
Table 2 Knowledge of Factors Contributing to Antibiotic Resistance

\begin{tabular}{lll}
\hline & Mean & SD \\
\hline $\begin{array}{l}\text { Widespread use of antibiotics } \\
\begin{array}{l}\text { Overuse of broad spectrum } \\
\text { antibiotics }\end{array}\end{array}$ & 2.79 & .48 \\
$\begin{array}{l}\text { Inappropriate use of antibiotic } \\
\text { therapy }\end{array}$ & 2.61 & .55 \\
$\begin{array}{l}\text { Inappropriate initial choice of } \\
\text { antibiotics }\end{array}$ & 2.58 & .60 \\
$\begin{array}{l}\text { Lack of guidelines on antibiotic } \\
\text { usage }\end{array}$ & 2.17 & .81 \\
$\begin{array}{l}\text { Patients' demand for antibiotics } \\
\text { Role of pharmaceutical companies } \\
\text { in promoting the use of antibiotics }\end{array}$ & 1.90 & .80 \\
$\begin{array}{l}\text { Inadequate hand washing } \\
\text { Use of antibiotics in the livestock } \\
\text { industry }\end{array}$ & 1.75 & .79 \\
\hline & 1.47 & .95 \\
& 1.41 & 1.03 \\
& & \\
\hline
\end{tabular}

correlated to female sex $(p=0.004)$, having postgraduate training $(p=0.001)$ and $>$ four years post graduation $(p=0.03)$.

\section{Knowledge of preventing or containing antibiotic resistance} Physician education programmes $(2.67 \pm 0.66)$ and access to timely laboratory reports $(2.67 \pm 0.67)$ were both considered most important and antibiotic restriction $(2.04 \pm 0.80)$ and cycling $(1.97 \pm 0.92)$ least important (Table 3).

The overall score for knowledge of factors to contain resistance showed the majority of respondents had good knowledge (83\%), 9.5\% had average knowledge and 7.5\% poor. A good score was positively correlated to type of current practice $(p=0.04)$, with the highest scores in physicians whose practice was mainly hospital based.

\section{Antibiotics more prone to inducing resistance}

Respondents incorrectly thought that amoxicillinclavulanic acid had the greatest potential to induce resistance $(1.51 \pm 0.7)$, but correctly identified ceftriaxone $(1.31 \pm 0.75)$ and ciprofloxacin $(1.23 \pm 0.78)$ as inducers of resistance. Antibiotics thought to have the least potential to induce resistance were amikacin $(0.94$ $\pm 0.7)$ and the carbapenems $(0.98 \pm 0.7)$. (Table 4).

Most (58.7\%) had good knowledge, 25\% had average knowledge and the remainder's knowledge was poor (16\%). This score was correlated to type of practice $(p=0.005)$; years post graduation $(p=0.018)$ and postgraduate training $(p=0.013)$. Physicians who were primarily hospital-based, who had been in practice between 10 and 14 years or had postgraduate training had the highest scores.

\section{Optimal duration of therapy}

Most physicians would treat an uncomplicated urinary tract infection for 7-10 days (43\%), 30\% would treat for five days and $24 \%$ for less than five days. For a group A streptococcus pharyngitis, 64\% would treat for seven to ten days, $19 \%$ for five days and 12\% for 14 days. A community-acquired pneumonia would be treated for 7-10 days by the majority (75\%), and five days $(13 \%)$ and 14 days $(8 \%)$ by the remainder. A Staphylococcus aureus bacteremia would be prescribed 14 days of antibiotics by $48 \%$ of respondents, seven to ten days by $36 \%$ and > 14 days by $12 \%$.

\section{Complications related to antibiotic resistance}

Respondents felt that increased costs related to care (73\%) and prolonged hospital stay (66\%) were the most frequent complications of ABR. Death and organ failure (33\% respectively) were thought to be less common.

\section{Attitude}

\section{Opinion on restriction of antibiotics}

The antibiotics considered suitable for a hospitalrestricted list (multiple antibiotics could be chosen) included vancomycin (81\%), carbapenems (79\%) and piperacillin/tazobactam (65\%). Most did not think that ciprofloxacin $(27 \%)$, ceftazidime $(28 \%)$ or ceftriaxone (14\%) should be restricted. 36\% of respondents felt the current level of restriction should be increased, $25 \%$ felt they should be maintained and $4 \%$ advocated a decrease.

Table 3 Knowledge of Preventing or Containing Antibiotic Resistance

\begin{tabular}{|c|c|c|}
\hline & Mean & SD \\
\hline $\begin{array}{l}\text { Ongoing physician educational } \\
\text { programmes }\end{array}$ & 2.67 & .659 \\
\hline Access to timely lab reports & 2.67 & .674 \\
\hline $\begin{array}{l}\text { Development of national antibiotic } \\
\text { guidelines }\end{array}$ & 2.63 & .684 \\
\hline Access to microbiology consultations & 2.58 & .694 \\
\hline $\begin{array}{l}\text { Development of better diagnostic } \\
\text { tests to differentiate bacterial from } \\
\text { viral infection }\end{array}$ & 2.53 & .745 \\
\hline Public educational programmes & 2.44 & .753 \\
\hline $\begin{array}{l}\text { Antibiotic restriction: requiring a } \\
\text { countersignature by a consultant } \\
\text { or microbiologist }\end{array}$ & 2.04 & .800 \\
\hline $\begin{array}{l}\text { Antibiotic cycling: switching } \\
\text { routine use from one class to } \\
\text { another at a regular intervals }\end{array}$ & 1.97 & .920 \\
\hline
\end{tabular}


Table 4 Knowledge of Inducing Antibiotic Resistance

\begin{tabular}{lll}
\hline & Mean & SD \\
\hline Amoxicillin-clavulanic acid & 1.51 & .70 \\
Ceftriaxone & 1.31 & .75 \\
Ciprofloxacin & 1.23 & .78 \\
Ceftazidime & 1.13 & .74 \\
Piperacillin-tazobactam & 1.01 & .70 \\
Meropenem/Imipenem & .98 & .70 \\
Amikacin & .94 & .65 \\
\hline
\end{tabular}

$(0=$ don't know, 1 = less likely, 2 = more likely $)$

\section{Practice}

\section{Personal experience with MDROs}

Physicians identified MRSA (65\% of respondents), multiresistant Pseudomonas aeruginosa and ESBL Eschericha coli (35\% each), ESBL Klebsiella pneumoniae (28\%), penicillin resistant Streptococcus pneumoniae (PRSP, 27\%) and Vancomycin Resistant Enterococcus (VRE) (19\%) within their personal practices. Hospital physicians and those with both a hospital and outpatientbased practice consistently reported higher personal experience with MDROs, except for PRSP. Hospital physicians reported less experience with PRSP (22\%) than outpatient-based (30\%) and those with a combined practice $(34 \%, p=0.03) .75 \%$ hospital-based, $72 \%$ of both and $41 \%$ outpatient-based physicians had experience with MRSA $(p<0.001)$.

\section{Choice of antibiotics}

The factors that commonly affected antibiotic choice included severity (91\%) and site (90\%) of infection; patient factors such as renal disease, immunocompromise and allergy (84\%); availability of antibiotics (84\%) and cost (58\%). Knowledge of patterns of ABR was important for $54 \%$. Only $5 \%$ of respondents admitted to being influenced by requests from the patient or their family and $2 \%$ to pressure from pharmaceutical companies.

For a community-acquired pneumonia, the most common initial empiric choices were amoxicillin-clavulanic acid (77\%) and erythromycin (38\%). For a hospital acquired pneumonia, ceftriaxone (38\%), ceftazidime (33\%) and piperacillin/tazobactam (31\%) were the most popular choices. Trimethoprim-sulfamethoxazole (52\%), amoxicillin-clavulanic acid (44\%) and ciprofloxacin (41\%) were commonly used for uncomplicated urinary tract infections. (Table 5) Physicians were allowed to choose more than one antibiotic for each type of infection, and so totals are greater than $100 \%$.

Forty-three percent (43\%) of respondents frequently take cultures prior to starting a course of antibiotics, $47 \%$ occasionally and only $7 \%$ always take cultures. Frequently taking cultures was more common amongst hospital physicians (53\%) than outpatient-based (24\%) or those who had a combined practice $(44 \%, p<0.001)$. Most (53\%) are able to get results within four to seven days, and $16 \%$ in less than three days. However, $27 \%$ complained that results would take over 1 week. $41 \%$ of respondents felt that their initial choice was correct based on laboratory reports "somewhat often" and 31\% "sometimes" $5 \%$ had never checked.

\section{Responses to culture reports}

Physicians were asked what their response would be to a culture report indicating the organisms isolated were resistant to the empiric antibiotic/s in a patient responding clinically. The majority (54\%) would change to antibiotics indicated by the report, 31\% would continue the present antibiotics, and $16 \%$ would add one of the susceptible antibiotics indicated by the report. When asked what their response would be to a culture report showing an isolate sensitive to current antibiotics, but also to a narrower-spectrum antibiotic in a patient who is responding clinically, only $21 \%$ would de-escalate to the narrow-spectrum therapy.

\section{Physicians' treatment decisions when antibiotics are not indicated}

When asked about their practice if they thought antibiotics were not indicated, $92 \%$ would explain to their patients why they were not needed, $88 \%$ would guide them on seeking follow-up care if symptoms do not improve, $84 \%$ would provide medications for relief of symptoms and $71 \%$ would educate on the harm of taking unnecessary antibiotics. Only 6\% admitted to prescribing antibiotics if the patient demanded it. However, when further asked if they had ever prescribed antibiotics only because of patients' insistence, $21 \%$ (12\% hospital based, $31 \%$ outpatient based) admitted to doing that.

\section{Additional training}

Only 34\% of respondents thought that their knowledge of antibiotics and ABR was good or very good; the majority (53\%) felt it was average and this was the same for both hospital and outpatient-based physicians. The majority of respondents (86\%) thought they needed a refresher course in ABR and prescription. Just over half of the respondents (52\%) had further training in the use of antibiotics post graduation, either through a seminar $(86 \%)$ or a formal course $(14 \%)$.

The majority of physicians (74\%) turned to the Internet when they needed further information on infection management. Other sources included consultation with local experts (54\%), other colleagues (43\%), national guidelines (41\%) and textbooks (40\%). Only 35\% would consult institutional guidelines. 
Table 5 Choices of Empiric Antibiotics

\begin{tabular}{|c|c|c|c|c|}
\hline & $\begin{array}{l}\text { Community acquired } \\
\text { pneumonia }\end{array}$ & $\begin{array}{l}\text { Hospital acquired } \\
\text { pneumonia }\end{array}$ & $\begin{array}{l}\text { Uncomplicated urinary } \\
\text { tract infection }\end{array}$ & Overal \\
\hline $\begin{array}{l}\text { Amoxicillin-clavulanic } \\
\text { acid }\end{array}$ & $77 \%$ & $21 \%$ & $44 \%$ & $53 \%$ \\
\hline Erythromycin & $38 \%$ & $11 \%$ & $3 \%$ & $14 \%$ \\
\hline Ceftriaxone & $21 \%$ & $38 \%$ & $6 \%$ & $22 \%$ \\
\hline Cefuroxime & $15 \%$ & $16 \%$ & $10 \%$ & $14 \%$ \\
\hline Ciprofloxacillin & $7 \%$ & $13 \%$ & $41 \%$ & $20 \%$ \\
\hline Bactrim & $7 \%$ & $5 \%$ & $52 \%$ & $18 \%$ \\
\hline Ceftazidime & $7 \%$ & $33 \%$ & $3 \%$ & $13 \%$ \\
\hline Metronidazole & $6 \%$ & $8 \%$ & $5 \%$ & $13 \%$ \\
\hline Piperacillin/tazobactam & $6 \%$ & $31 \%$ & $3 \%$ & $11 \%$ \\
\hline Meropenem & $4 \%$ & $12 \%$ & $2 \%$ & $5 \%$ \\
\hline Amikacin & $3 \%$ & $9 \%$ & $4 \%$ & $5 \%$ \\
\hline
\end{tabular}

\section{Discussion}

This is the first national survey of Jamaican doctors regarding their knowledge and opinions on antibiotic resistance and their prescribing practices. Physicians from all health regions were included from a wide range of disciplines and clinical experience.

\section{Knowledge and attitudes}

Eight out of 10 doctors (82\%) recognized the magnitude of ABR globally, but less were convinced of this locally (73\%) and even less so in their personal practice (53\%). The danger of this finding is that physicians could become detached from the problem, making them less likely to try to contain it. ABR is more common in the hospital setting and this was reflected in the responses of the hospital doctors. The authors have observed that the prohibitive cost and delay in retrieving microbiology reports in some areas have adversely affected the Jamaican physicians' perceptions of the value of obtaining routine cultures. This could explain why only $7 \%$ of physicians always take cultures for a suspected infection. Hence, there is little reminder of prevailing resistance patterns.

Most physicians appreciated the influence of widespread use, inappropriate choices and overuse of broadspectrum antibiotics as drivers of ABR $[4,18]$. However a significant number failed to recognize important drivers of resistance such as inadequate hand hygiene and antibiotic usage in the livestock industry $[4,5]$. When the objective assessment of their overall knowledge of $A B R$ was compared to their own personal assessment, there was good correlation with $57 \%$ receiving an average score objectively, and $54 \%$ perceiving their knowledge as average.

Ongoing educational programmes, the development of national antibiotic guidelines, access to microbiology consultation, as well as improved laboratory services were thought to be most useful in containing $A B R$. There are only two medical microbiologists and one infectious disease specialist for the public health sector across the entire island. This needs to be urgently addressed as part of a national programme. Access to timely laboratory reports continues to be a challenge in this resource limited setting, where there are only few laboratories with limited diagnostic capacity, often using manual systems. Although this problem would appear to be a local one, its potential impact could be global because of Jamaica's position as a popular destination. The role of inadequate rapid point of care (POC) tests to differentiate between viral and bacterial infections was also clearly appreciated by the respondents as being an important factor to contain resistance. POC tests are those that are performed at the bedside and generate convenient and rapid results [24]. These would quickly differentiate between viral and bacterial infections such as Group A Streptococcus and urinary Streptococcus pneumoniae. Unfortunately there are only a few rapid POC tests and this is a problem internationally [25]. This is particularly highlighted by upper respiratory tract infections which are common worldwide and are often overtreated by antibiotics in the absence of rapid POCs [26]. Factors such as antibiotic cycling and restriction, that would confine the physicians' prescribing practice, were not perceived to be as important. This was confirmed by the fact that only just over one third (36\%) thought that current antibiotic restriction policies should be increased.

Just over half of the physicians (59\%) surveyed understood that some antibiotics are more prone to inducing resistance than others. As expected, physicians in the hospital setting had better knowledge, but there is room for more education across the board, such as seminars, 
workshops, conferences, newsletters and official antibiotic guidelines. Although the third generation cephalosporins and fluoroquinolones have a high propensity towards resistance induction [27] they remain some of the more prescribed antibiotics. Ceftriaxone was the second most commonly chosen empiric antibiotic overall followed by ciprofloxacin. The response to optimal duration of antibiotic therapy varied widely and highlights the need for national and institutional guidelines.

\section{Practice}

Although $65 \%$ of the respondents identified MRSA as the most common resistant organism seen in their practice, it should be noted that at the major referral hospital in the island, MRSA prevalence rate for the past three years has been less than 4\% [16]. This information has been widely communicated to local physicians through conferences and workshops. Typing of the MRSA isolates retrieved from this hospital showed that only $29 \%$ were scc mec IV type (E. Finlayson, unpub. Data [28]. It should also be noted that $30 \%$ and $24 \%$ of the MRSA isolates retrieved in 2008 were resistant to low level and high level mupirocin respectively [29] highlighting again the need for constant surveillance.

Similarly, the prevalence rates for VRE have been less than $1 \%$ for the past four years in the same hospital (A Nicholson, unpub. data), even though $19 \%$ of physicians reported having seen this organism in their practice. As to be expected, hospital physicians reported a higher incidence of MDROs, and PRSPs were more commonly seen in the community.

Although factors influencing choice were appropriate, knowledge of local antibiograms was not always included. Again, this could be related to limited laboratory resources that reduce the availability of culture results and objective data. In the absence of national guidelines, the tendency is for the physicians to use international guidelines, as evidenced by the empiric choices for community and hospital acquired pneumonia and urinary tract infections. This finding also corresponds with the physicians' high use of the Internet for information (74\%), far more than consulting local experts (54\%). From the limited susceptibility data available, it is clear that local susceptibility patterns, eg Staphylococcus aureus (3.2\% MRSA) and Enterococcus, $(<1 \%$ VRE) (are different from those reported in developed countries, and hence empiric choices should not be solely based on international guidelines. Streptococcus pneumoniae is recognized as the commonest cause of community acquired pneumonia and recent data showed a $8 \%$ resistance to penicillin (IV) for all isolates nationally (A. Foster, 2015 unpub. data), which is far less than the $24 \%$ resistance seen in North America [30]. Where penicillin resistance is low, the use of penicillin/amoxicillin-clavulanic acid for first line therapy is appropriate.
Physicians were more inclined to change to broadspectrum antibiotics and reluctant to de-escalate, even in the face of laboratory data [31]. This type of practice is expensive, and ultimately drives resistance [32]. In this era of $A B R$ it is important for physicians to achieve optimal outcomes by combining laboratory and clinical data. This study found that only $21 \%$ of physicians would deescalate therapy, while a 2010 single-centre Jamaican study showed that only $7.7 \%$ actually practiced deescalation [33]. There has been some improvement through education of physicians as to the importance of the practice, and attention had been drawn to the results of the 2010 study in conferences, workshops and small group sessions by local microbiologists. Encouragement to de-escalate should continue to be a target in future programmes.

It is encouraging to see that the physicians were paying attention to the need for patient education ranging from explanations of the dangers of unnecessary antibiotics to guiding them to seek follow-up care if necessary. Although 6\% admitted to prescribing antibiotics on demand, a further $15 \%$ admitted to having done so in the past. This may be the result of increased of continuing education via conferences and workshops, some of which are mandatory. We would have expected more response to patient pressure, especially in the private setting. This is a positive finding, but more work is needed to further reduce this figure.

The majority of physicians were interested in further educational courses on antibiotic resistance. The results of this survey will guide the development of these courses, which could be in the form of hospital based workshops, orientation of new staff and medical conferences.

The major limitation of this study is that it relied on self-reporting by physicians as well as recall of past practices. This could have led to either under or over reporting and recall bias, which may have affected results. Further qualitative research using focus groups, for example, could highlight reasons for some of the practices seen, such as the reluctance to de-escalate therapy, and this could guide interventions.

\section{Conclusions}

Physicians in this study were aware of the problem of ABR, but downplayed its significance nationally and personally. Most had only average knowledge of factors driving resistance, but good knowledge of factors to control resistance. They tended to use international guidelines when making empiric choices, to choose highpowered antibiotics even when patients were improving and to resist de-escalation when appropriate. These are all important targets for a national campaign. Strengthening laboratory medicine in resource limited countries 
such as Jamaica and most of the English speaking Caribbean countries would play a major role in restricting the emergence of antibiotic resistance. This would also involve training more clinical microbiologists, infectious disease physicians, pharmacists and other experts. This would help to determine prevalent organisms and their antibiograms resulting in more accurate and cost effective therapy. The savings from this could then be invested in an antimicrobial stewardship programme. Policy changes are also needed from local Ministries of Health and national medical associations to provide guidance and monitoring.

\section{Abbreviations}

ABR: Antibiotic resistance; ESBL: Extended spectrum betalactamase; MDROs: Multidrug resistant organisms; $\mathrm{MOH}$ : Ministry of Health; MRSA: Methicillin resistant Staphylococcus aureus; PRSPs: Penicillin resistant Streptococcus pneumoniae; SPSS: Statistical Analysis in the Social Sciences: VRE: Vancomycin resistant Enterococcus

\section{Acknowledgments}

This project was supported by the National Health Fund, Jamaica.

\section{Disclaimers}

The opinions expressed by authors contributing to this journal do not necessarily reflect the opinions of the National Health Fund, Jamaica or the institutions with which the authors are affiliated.

\section{Funding}

Funding for this project was obtained through a grant received from the National Health Fund. The funds received were used for data collection and analysis.

\section{Availability of data and materials}

The datasets used and/or analysed during the current study are available from the corresponding author on reasonable request.

\section{Authors' contributions}

AN being the primary author of this paper participated in every aspect of this research project from its conceptualization to its execution and write up. IT, LW, LC, SJ, JB and LR also helped to design the study. CT-R helped with data collection. All authors helped to analyse the data and write the paper. All authors have read and approved the final manuscript.

\section{Authors' information}

Dr. Alison Nicholson is a Consultant Medical Microbiologist in the Department of Microbiology at the University of the West Indies, Mona, where she is currently the Head of Department. Dr. Nicholson has an interest in antibiotic resistance and infection control.

\section{Ethics approval and consent to participate}

This study was approved by the Ministry of Health and the University of the West Indies Ethics Committees.

\section{Consent for publication}

N/A

NB Study participants gave consent to participate in the study, however there is nothing in the paper that can be used to uniquely identify them

\section{Competing interests}

The authors declare they have no competing interests.

\section{Publisher's Note}

Springer Nature remains neutral with regard to jurisdictional claims in published maps and institutional affiliations.

\section{Author details}

'Department of Microbiology, The University of the West Indies (UWI), Kingston, Jamaica. ${ }^{2}$ Department of Surgery, Radiology, Anaesthesia and Intensive Care, UWI, Kingston, Jamaica. ${ }^{3}$ UWI CARIMAC, Kingston, Jamaica. ${ }^{4}$ School of Education, UWI, Kingston, Jamaica. ${ }^{5}$ Department of Government, UWI, Kingston, Jamaica. ${ }^{6}$ Department of Medicine, UWI, Kingston, Jamaica. ${ }^{7}$ Ministry of Health, Kingston, Jamaica.

Received: 27 October 2017 Accepted: 7 February 2018

Published online: 15 February 2018

\section{References}

1. Levy SB, O'Brien TF. Global Antimicrobial Resistance Alerts and Implications. CID. 2005;41:219-20. (Suppl 4)

2. Livermore D. Current epidemiology and growing resistance of gram-negative pathogens. Korean J Intern Med. 2012;27:28-142.

3. Laxminarayan R, Duse A, Wattal C, Zaidi A, Wertheim H, Sump N, et al. Antibiotic resistance - the need for global solutions. Lancet Infect Dis. 2013; 13(12):1057-98.

4. Ventola C. The antibiotic resistance crisis. Pharm Ther. 2015:40(4):277-83.

5. The World Health Organization. Antimicrobial Resistance. The World Health Organization Media Centre. Fact sheet №194. 2015. https://warwick.ac.uk/ fac/sci/lifesci/outreach/headstart_2016/who_antimicrobial_resistance.pdf. Accessed 1 Sept 2016

6. Aminov R. A brief history of the antibiotic era: lessons learned and challenges for the future. Front Microbiol. 2010:1:134

7. Smith R, Coast J. The true cost of antimicrobial resistance. BMJ. 2013;346:1-5.

8. Akpaka PE, Swanston WH. Phenotypic detection and occurrence of extended-spectrum beta-lactamases in clinical isolates of Klebsiella pneumoniae and Escherichia coli at a tertiary Hospital in Trinidad \& Tobago. Braz J Infect Dis. 2016;12(6):516-20.

9. Akpaka PE, Kissoon S, Jayaratne P. Molecular Analysis of VancomycinResistant Enterococci Isolated from Regional Hospitals in Trinidad and Tobago. Adv Med. 2016; https://www.hindawi.com/journals/amed/2016/ 8762691/. Accessed 01 Sep 2016.

10. Akpaka PE, Roberts R, Monecke S. Molecular characterization of antimicrobial resistance genes against Staphylococcus aureus isolates from Trinidad and Tobago. J Infect Public Health. 2016; http://www.ncbi.nlm.nih.gov/pubmed/ 27328777. Accessed 01 Sep 2016

11. Hariharan S, Nanduri SB, Moseley HS, Areti KY, Jonnalagadda R. Spectrum of microbes and antimicrobial resistance in a surgical intensive care unit. Am J Infect Control. 2003;31(5):280-7.

12. Levett PN, Holt HA, McGowan AP. Resistance to third-generation cephalosporins in Barbados. West Indian Med J. 1993;42(2):69-71.

13. Thoms-Rodriguez CA, Mazzulli T, Christian N, Willey B, Boyd DA, Mataseje LF, et al. New Delhi metallo-ß-lactamase in Jamaica. J Infect Dev Ctries. 2016;10(2):183-7.

14. Souli M, Galani I, Giamarellou H. Emergence Of extensively drug-resistant and pandrug-resistant gram-negative bacilli in Europe. Euro Surveill. 2008; 47(13):1-11.

15. Christian N, Roye-Green K, Smikle M. Molecular epidemiology of multidrug resistant extended spectrum beta-lactamase producing Klebsiella pneumoniae at a Jamaican hospital, 2000-2004. BMC Microbiol:2010. http://bmcmicrobiol.biomedcentral.com/articles/10.1186/ 1471-2180-10-27. Accessed 01 Sep 2016

16. Nicholson AM, Ledgister S, Williams T, Robinson S, Gayle P, Lindo T, et al. Distribution of nosocomial organisms and their resistance patterns in the intensive care unit of the University Hospital of the West Indies, Kingston. Jam W Indian Med J. 2009;58(2):142-8. (ISSN 0043-3144)

17. Thoms-Rodriguez C, Mazzulli T, Christian N, Willey B, Nicholson AM. Meropenem Efflux in Pseudomonas aeruginosa at a Tertiary Care Hospital in Jamaica. W Indian Med J. 2016; https://www.mona.uwi.edu/fms/wimj/ article/2678. Accessed 01 Sep 2016

18. Hamilton-Miller JMT. Use and abuse of antibiotics. Br J Clin Pharm. 1984;18:469-74

19. Tennant I, Nicholson A, Gordon-Strachan GM, Thoms C, Chin V, Didier MA A survey of physicians' knowledge and attitudes regarding antimicrobial resistance and antibiotic prescribing practices at the university hospital of the west indies. W Indian Med J. 2010;59(2):165-70.

20. Johnson $\mathrm{K}$ and Bartlett $\mathrm{K}$. The role of tourism in national human resource development: a Jamaican perspective. Human Resource Development 
International. 2013. http://www.tandfonline.com/doi/abs/10.1080/13678868. 2013.771867. Accessed 01 Sep 2016.

21. The Statistical Institute of Jamaica. The Statistical Institute of Jamaica Website. 2014. http://statinja.gov.jm/demo_socialstats/population.aspx. Accessed 01 Sep 2016.

22. The World Health Organization. Second Meeting of the Subcommittee of the Expert Committee on the Selection and Use of Essential Medicines. Use of Ceftazidime in Children and Options for Treating Pseudomonas Infections. Geneva : s.n., 2008

23. Pedhazur EJ, Pedhazur-Schmelkin LP. Measurement, design and analysis: an integrated approach. New York: Psychology Press; 1991. p. 109.

24. Peeling RW, Mabey D. Point-of-care tests for diagnosing infections in the developing world. Clin Microbiol Infect. 2010;18(16):1062-9.

25. Society for Healthcare Epidemiology of America and Infectious Diseases Society of America. Policy statement on antimicrobial stewardship by the Society for Healthcare Epidemiology of America (SHEA), the Infectious Diseases Society of America (IDSA), and the Pediatric Infectious Diseases Society (PIDS). Infect Control Hosp Epidemiol. 2012; 33(4):322-3.

26. Leichman AK. New diagnostic test distinguishes bacterial from viral infections. Israel 21C. https://www.israel21c.org/new-diagnostic-testdistinguishes-bacterial-from-viral-infections/. Accessed 16 Jan 2018.

27. Ruiza J, Jurado A, Garcia-Méndez E, Marco F, Aguilar L, Jiménez de Anta T, et al. Frequency of selection of fluoroquinolone-resistant mutants of Neisseria gonorrhoeae exposed to gemifloxacin and four other quinolones. J Antimicrob Chemother. 2001:48(4):545-8.

28. Brown P. Multiple-locus VNTR analyses of methicillin-resistant Staphylococcus aureus from Jamaica. Infect Dis (Auckl). 2015;8:31-8.

29. Nicholson AM, Thoms C, Wint H, Didier M, Willis R, McMorris N, et al. The detection of mupirocin resistance and the distribution of methicillin-resistant Staphylococcus aureus at the University Hospital of the West Indies, Jamaica. West Indian Med J. 2010;59(5):509-13.

30. Whitney C, Farley M, Hadler J, Harrison L, Lexau C, Reingold A, et al. Increasing prevalence of multidrug-resistant Streptococcus pneumoniae in the United States. N Engl J Med. 2000;343:1917-192.

31. Masterton R. Antibiotic De-Escalation. Crit Care Clin. 2011;27:149-62.

32. Hayashi Y, Paterson D. Strategies for reduction in duration of antibiotic use in hospitalized patients. CID. 2011;52:1232-40.

33. Chin V, Harding HE, Tennant I, Soogrim D, Gordon-Strachan GM Frankson MA. Dynamics of antibiotic usage in the intensive care unit at the University Hospital of the West Indies. West Indian Med J. 2010; 59(2):159-64.

\section{Submit your next manuscript to BioMed Central and we will help you at every step:}

- We accept pre-submission inquiries

- Our selector tool helps you to find the most relevant journal

- We provide round the clock customer support

- Convenient online submission

- Thorough peer review

- Inclusion in PubMed and all major indexing services

- Maximum visibility for your research

Submit your manuscript at www.biomedcentral.com/submit

) Biomed Central 